\title{
PROPUESTA METODOLÓGICA PARA FOMENTAR LA IGUALDAD DE GÉNERO EN EL AULA ESCOLAR
}

Yisenia Solís Pérez ${ }^{1}$

\section{Resumen}

Este trabajo se denomina propuesta metodológica para fortalecer la Igualdad de Género en el Aula Escolar, con niños y niñas de la escuela primaria. Como educadora, he querido aportar a través de mis experiencias vividas, algunas estrategias que permitan fomentar en las y los estudiantes una educación más justa e igualitaria.

Conocedora, de las diferentes prácticas sexistas y estereotipos altamente arraigados en nuestra sociedad, los cuales obstaculizan que algunas mujeres logren desenvolverse según sus propias capacidades y potencialidades, limitándolas a cumplir con el papel que la sociedad les asigna según su sexo, deseo aportar una propuesta para que las y los estudiantes vivan en el aula una igualdad real. Es la escuela uno de los agentes socializadores más importantes y en donde se debe propiciar el cambio en pro de una educación de equidad.

El trabajo a nivel de aula permitirá disminuir los esquemas discriminatorios y será un gran logro en beneficio de las futuras generaciones. Las interrelaciones que se viven en esa microcultura llamada aula, son muy enriquecedoras y variadas, por lo que es un lugar propicio para iniciar cambios en materia de género.

\section{Abstract}

This work is named methodological proposed to fortify the equality of kind in the school classroom, with children and girls of the primary school. As teacher, I have wanted to contribute through my lived experiences, some strategies that they allow to foment in ours students a more just and egalitarian education.

Knowledgeable, of the different sexist practices and stereotypes highly

\footnotetext{
${ }^{1}$ Actualmente labora como profesora y Asistente de Dirección en la Escuela Llorente de Flores, Heredia. Licenciada en Administración Educativa de la Universidad Central y Licenciada en Ciencias de la Educación con concentración en Educación Básica I y II Ciclos Universidad Nacional.
} 
established in our society, that hinder some women manage to be unfold according to their own capacities and potentials, bordering them to comply with the role that the society assigns them according to their sex, it is that I desire to put an propose in order the students live in the classroom a real equality. Being the school one of the more important agents of socialization, and where it is necessary to propitiate the change in favour of an education of equity.
The work to level of classroom will allow diminishing the discriminatory schemes and will be a great achievement in benefit of the future generations. The interrelationships that live in that small cuiture called classroom, are very wealthproducing and varied, for which it is a favourable place to initiate changes in matter of kind.

Palabras claves: género, equidad, escuela y sociedad.

\section{JUSTIFICACIÓN}

$\mathrm{D}$ urante siglos, la mujer y el hombre han estado sometidos a una gran cantidad de estereotipos y prácticas sexistas, los cuales han conducido a que en nuestra sociedad haya una desigualdad de género, en los diferentes ámbitos: en lo social, económico, político y educativo. Todas estas prácticas, han logrado reprimir y someter a la mujer, la cual es vista como inferior al varón. Esta inferioridad es tomada como algo natural y es universalmente aceptada por una sociedad patriarcal que ha puesto a la mujer en desventaja con respecto al hombre, ya que la participación real de ella en las esferas sociales y políticas son muy limitadas; asimismo, en el ámbito laboral, la discriminación es tal, que hasta el salario es inferior. El sometimiento de la mujer al machismo en algunos casos ha sido tanto, que ella misma ha contribuido a su perpetuación y reforzamiento y lo ha transmitido de generación en generación. Todo esto le ha impedido a la mujer desarrollar sus verdaderas potencialidades.

En los hogares costarricenses, se siguen reforzando estos esquemas discriminatorios y las mujeres aún son víctimas. De allí que sea importante elaborar una propuesta sobre género, que permita a los y las docentes fomentar la igualdad entre hombres y mujeres, y así crecer y desarrollarse de acuerdo con sus propias expectativas e intereses, dependiendo de las potencialidades de cada quien, y sin distinción de sexo.

Si se fortalece esta área, se pueden mejorar las relaciones interpersonales que ahí se viven, en beneficio de ambos géneros. Además, cada uno de los 
y las participantes llevaría las experiencias y aprendizajes al hogar, para lograr con ello, poco a poco, ir cambiando el papel de la mujer en la familia.

\section{ANTECEDENTES HISTÓRICOS SOBRE LA IGUALDAD DE GÉNERO}

Para comprender mejor la importancia de la igualdad de género y darle el valor que este tema realmente merece, se hace necesario remontarse a los orígenes de la desigualdad social, económica, política, educativa, que han vivido las mujeres a través de muchos siglos. En este espacio, esto es imposible, debido a que se tendría que explicar toda la historia de la humanidad; de ahí que se exponen, en forma general, algunos aspectos relevantes que permitan describir la sociedad a través del tiempo según su evolución.

\section{El patriarcado}

Nuestra sociedad se caracteriza por ser una sociedad "Patriarcal". La Real Academia Española en su diccionario electrónico, punto 5, define patriarcado como: "Organización social en que la autoridad es ejercida por un varón, jefe de cada familia, extendiéndose este poder a los parientes aún lejanos de un mismo linaje."

En una sociedad patriarcal, el hombre tiene la supremacía, pues él es el fuerte, el inteligente, el habilidoso, el que tiene la razón y el que manda. Así esta sociedad patriarcal ha hecho esfuerzos descomunales por buscar explicaciones que justifiquen la inferioridad de la mujer, como algo justo y natural. Estas explicaciones se fundamentaron a través de la religión, la ciencia y el lenguaje.

Algunas teorías, leyes o mitos, condujeron al reforzamiento de la supremacía masculina y tergiversaron el papel real de la mujer.

\section{EVOLUCIÓN DE LA IGUALDAD DE GÉNERO}

El concepto de género se desarrolló con mayor énfasis en el campo de las Ciencias Sociales. Este empezó a tener importancia en la década de los años setenta, con la aparición del feminismo, el cual surge primeramente en Estados Unidos y luego en Europa; luego tomó fuerza en otros países de América y África. En un principio, este concepto lo desarrollaron feministas preocupadas por la percepción acerca de su sexo y de la supremacía masculina, y empiezan a luchar y a promover la igualdad entre ambos sexos. Las 
luchas de estos grupos, poco a poco, fueron ganando terreno, ya en 1975 se realizó la Conferencia Mundial de la Mujer, convocada por las Naciones Unidas para promover la igualdad y asegurar la integración plena de la mujer dentro del desarrollo y fortalecimiento de cada país.

\section{EVOLUCIÓN DE LA IGUALDAD DE GÉNERO EN COSTA RICA}

A lo largo de la historia de la humanidad, y específicamente, en el caso de Costa Rica, la lucha por los derechos de la mujer ha sido larga y difícil, se han conseguido así, el derecho a la educación, al voto, a la licencia por maternidad, a no ser acosadas sexualmente, entre otros. Estos logros son importantes pero no suficientes. A raíz de ello, en la década de los ochenta, se empieza a dar mayor énfasis, en nuestro país, a la igualdad de género, gracias a los avances que en esta materia se habían logrado mundialmente. Por tal motivo, se plantean en Costa Rica leyes y programas tendientes a buscar la equidad entre los hombres y las mujeres, fomentando que ambos sean tratados y respetados por igual.

Se crean leyes tales como: Ley de Promoción de la Igualdad de la Mujer, Código de la Niñez y la Adolescencia, Ley contra el Hostigamiento Sexual en el Empleo y la Docencia, Ley contra la Violencia Doméstica, además de un Plan Nacional para la Atención y Prevención de la Violencia Intrafamiliar. Nacieron también instituciones encargadas de atender y prevenir la violencia, específicamente, contra la mujer, como: el Ministerio de la Mujer, La Delegación de la Mujer, Centro Nacional para el Desarrollo de la Mujer y la Familia, Mujer agredida, Ser y Crecer.

Todos estos programas y leyes han coincidido en que la desigualdad entre hombres y mujeres, se debe a la socialización diferenciada proveniente del hogar, de la escuela, la iglesia y los medios de comunicación, los cuales, refuerzan la transmisión de esquemas discriminatorios y conducen posteriormente a la agresión y violencia contra la mujer.

Es así, como en 1982 se emprenden acciones para eliminar los contenidos sexistas, dentro de la educación formal costarricense, con la firma de un convenio de cooperación interinstitucional entre el Ministerio de Educación Pública y el Ministerio de Cultura, Juventud y Deportes, a través del Centro Nacional para el Desarrollo de la Mujer y la Familia. Su objetivo era promover la actualización de los programas y planes de estudio y los textos escolares, de manera que no se refuercen patrones de conducta diferentes para cada sexo. La Comisión encargada de tal propósito plantea, ante diferentes instancias 
del Ministerio de Educación, una serie de recomendaciones dirigidas al logro de la igualdad de oportunidades entre hombres y mujeres.

\section{SOCIALIZACIÓN DESDE UNA PERSPECTIVA TRADICIONAL}

Para abordar el tema de socialización, se hace necesario plantear las diferencias entre: sexo y género, o también llamado, sexo biológico y sexo social. El sexo es la condición biológica que conlleva a que los seres humanos tengan diferencias físicas y anatómicas y a que se les clasifique, por ello, en hombres y mujeres. Al nacer una persona, se le define como niño o niña no al azar, sino por sus órganos sexuales y de reproducción.

Sobre el sexo biológico, se han construido papeles sociales y culturales distintos para los hombres y las mujeres, y estos precisamente son funciones que se atribuyen a cada sexo, lo que llamaremos sexo social o género.

\section{SOCIALIZACIÓN DESDE UNA PERSPECTIVA DE IGUALDAD DE GÉNERO}

La desigualdad de género, y con ello la discriminación de la mujer, es una práctica generalizada en nuestra sociedad patriarcal. Debido a ello, se hace necesario buscar una socialización que refuerce la igualdad entre los géneros.

La socialización desde una perspectiva de igualdad de género, busca la sensibilización, tanto de hombres como de mujeres, para que comprendan la importancia de la igualdad de género. Debe buscar, fomentar y reforzar las relaciones justas e igualitarias, para cambiar los papeles que tradicionalmente se les ha asignado a uno y otro modelo: femenino y masculino. Debe buscar, además, que cada persona pueda desarrollarse plenamente según sus potencialidades, sin que sea su sexo biológico el que determine sus funciones y que cada persona aprenda a valorarse como única e irrepetible.

Esta nueva visión de mundo tiene que ir transformando lentamente todos los agentes socializadores: escuela, iglesia. medios de comunicación, entre otros, y además, debe irse introduciendo en todos los ámbitos; personal, social y familiar. Para eso, ha de construirse nuevos modelos sociales, mediante estrategias creativas e innovadoras. que busquen crear y fomentar acciones tendientes a detectar y modificar los estereotipos sexistas. Estos nuevos modelos sociales deben cambiar los papeles que se han asignado tradicionalmente a ambos sexos, para que cada ser humano sea valorado sin subestimar un sexo sobre el otro. Así, desde pequeños y pequeñas, aprenderán 
que el esfuerzo, el interés personal y otros factores estructurales, y no el sexo biológico, es lo que determina su opción de vida y su realización como persona.

\section{LA ESCUELA COMO AGENTE SOCIALIZADOR TRADICIONAL}

La escuela es uno de los agentes socializadores más importantes; históricamente. Además, es un instrumento ideológico utilizado por las esferas de poder para mantener la dominación. De ahí la importancia que tiene todo ser humano en el proceso de socialización.

Las instituciones educativas son necesarias en el proceso de socialización, pues es a través de ellas, que se refuerzan o enriquecen las experiencias vividas por las niñas y los niños en la primera infancia, período de gran desarrollo intelectual; ahí adquieren las destrezas y comportamientos que los acompañarán durante toda la vida.

\section{LA ESCUELA COMO AGENTE SOCIALIZADOR DESDE UNA PERS- PECTIVA DE GÉNERO}

Los estereotipos sexistas son reforzados constantemente en nuestra sociedad, por eso, es necesario incentivar a todas las personas para su detección y eliminación, y qué mejor lugar para lograrlo que la escuela, pues es ahí se pueden fomentar actitudes y vivir experiencias tendientes a modificar dichos estereotipos, en las interrelaciones de aula y, consecuentemente, trascender estas actitudes en sus hogares.

Estas modificaciones deben abarcar todas las esferas, esto es, darse tanto a nivel de Ministerio de Educación Pública como en el salón de clase. Es indispensable entonces, que la igualdad de género sea tomada en cuenta al elaborar programas y planes de estudio, en los materiales didácticos, en los asesoramientos, en la elaboración de materiales dirigidos a las y los docentes o a las y los niños, en los mensajes publicitarios y con mucha más razón en la formación de los profesionales en educación.

Este último punto es de suma importancia, pues para que la escuela fortalezca la igualdad de género y deje de legitimar estereotipos sexistas, es necesario que las y los docentes se sensibilicen y comprendan realmente la importancia de erradicar esas prácticas discriminatorias en el aula. No se trata de que manejen el tema a nivel teórico, sino que lo practiquen y lo vivan diariamente, que enseñe con su ejemplo. No se trata de que "hagan lo que digo y no lo que hago", sino de que estén realmente convencidas y convencidos 
de que es necesario, construir relaciones más justas e igualitarias entre seres humanos, pues nadie puede dar lo que no tiene.

La investigación que dio origen a este artículo, nació de la aplicación de estrategias metodológicas que buscan promover la igualdad de género en algunos estudiantes de las escuelas. El estudio se llevó a cabo en las escuelas de la Gran Samaria y Llorente de Flores, ambas de la provincia de Heredia en el año 1998.

Para la investigación, se elaboró una propuesta con estrategias metodológicas variadas, atractivas e incentivadoras, para que las y los estudiantes, las y los participantes, vivieran en el aula escolar la igualdad de género, a través de actividades que le fueran placenteras. En la construcción del libro de trabajo, se utilizó el periódico como recurso didáctico, debido a que ofrecía informaciones e imágenes actualizadas, variadas y a un costo accesible para la mayoría de personas.

Para la recolección de la información, se contó con tres tipos de cuestionarios: uno dirigido a estudiantes, otro a docentes y finalmente uno aplicado a administrativos. Además, se utilizó la observación participante, esta es una técnica clásica muy usada por los etnógrafos, que consiste en que el investigador viva lo más que pueda con las personas o grupos, que desea investigar, compartiendo sus usos, costumbres, estilos y modalidades de vida.

A lo largo de este trabajo, se usó un portafolio como registro de todas las anotaciones pertinentes de lo observado en el aula, durante la aplicación de las estrategias metodológicas. El portafolio es una herramienta valiosa porque consiste en la recopilación de trabajos de las y los estudiantes, sin llevar un orden

La desigualdad de género, y con ello la discriminación de la mujer, es una práctica generalizada en nuestra sociedad patriarcal. Debido a ello. se hace necesario buscar una socializa. ción que refuerce la Igualdad entre los generos.

La socialización desde una perspectiva de igualdad de género, busca la sensibillzación, tanto de hombres como de mujeres, para que comprendan la importancia de la igualdad de genero. Debe bus car, fomentar y reforzar las re. laciones justas e Igualitarias. para cambiar los papeles que tradicionalmente se les ha asignado a uno y otro modelo: femenino y masculino. 
preestablecido, lo que permitió tener una visión enriquecedora del aprendizaje y del éxito.

Finalmente, se aplicó la propuesta metodológica que consiste en un folleto con estrategias metodológicas variadas y atractivas, que buscan fomentar la igualdad de género. El folleto se presta para recortar, pintar, armar, jugar, opinar, criticar, analizar y reflexionar. Consta de dieciocho experiencias, que proporcionan a los y las estudiantes, la motivación suficiente para que sientan la necesidad de vivir la igualdad de género en la escuela y por qué no, en el hogar.

Se seleccionaron dieciocho estrategias metodológicas debido a que son actividades lúdicas. Entre ellas hay: los juegos, los cuentos, la elaboración de títeres, los comentarios de actividades cotidianas e historietas. Este tipo de experiencias son llamativas para las y los estudiantes, y utilizadas como recursos didácticos, logran aprendizajes significativos y duraderos.

Cada estrategia metodológica posee un tema, la descripción de la técnica, el objetivo, el tiempo aproximado de desarrollo, los procedimientos y la evaluación. Se trabajó una por semana.

\section{RESULTADOS}

A continuación, se realizará una presentación y análisis de los resultados más significativos, obtenidos de la aplicación de los cuestionarios a docentes, administrativos, alumnos y alumnas, y en las observaciones (el portafolio) y del cuaderno de trabajo, dirigido a los alumnos y alumnas de segundo y cuatro grados, de las escuelas en estudio.

El desglose de estos datos, ofrece una visión clara del tema en estudio, con el fin de facilitar, la comprensión de la información para derivar de ella las conclusiones y recomendaciones.

La presentación de datos se hará por medio de cuadros o gráficos y registros anecdóticos. A continuación los resultados.

\section{OPINIÓN DE LAS Y LOS DOCENTES Y ADMINISTRATIVOS}

El primer objetivo de este estudio consistió en conocer la actitud de los ya las docentes, el equipo interdisciplinario y las directoras, con respecto a la igualdad de género. Los cuadros y gráficos siguientes reflejan los resultados obtenidos.

En el cuadro 1, podemos notar que hay una tendencia a favorecer a los hombres o las mujeres dependiendo de la cualidad a la que se refiere. En 


\section{CUADRO $\mathrm{N}^{\circ} 1$ \\ CUALIDADES QUE POSEEN LOS ALUMNOS Y LAS ALUMNAS}

\begin{tabular}{|l|c|c|c|c|c|c|}
\hline \multirow{2}{*}{ CRITERIOS } & \multicolumn{2}{|c|}{ NIÑOS } & \multicolumn{2}{c|}{ NIÑAS } & \multicolumn{2}{c|}{ AMBOS } \\
\cline { 2 - 7 } & Abs. & $\%$ & Abs. & $\%$ & Abs. & Ab. \\
\hline Espontáneos (as) & 18 & 58 & 10 & 32 & 3 & 10 \\
Activos (as) & 21 & 68 & 8 & 26 & 2 & 6 \\
Obedientes & 6 & 19 & 25 & 81 & - & - \\
Creativos (as) & 17 & 55 & 11 & 35 & 3 & 10 \\
Originales & 20 & 65 & 10 & 32 & 1 & 3 \\
Cariñosos (as) & 8 & 26 & 22 & 71 & 1 & 3 \\
Ordenados (as) & 5 & 16 & 20 & 65 & 6 & 19 \\
Estudiosos (as) & 8 & 26 & 16 & 52 & 7 & 22 \\
\hline
\end{tabular}

FUENTE: Cuestionario para docentes y administrativos.

síntesis se puede afirmar, los y las docentes, así como el administrativo de las instituciones en estudio, en su mayoría, opinan que los niños son más espontáneos, activos, creativos y originales, y las niñas más ordenadas, disciplinadas, estudiosas y cariñosas. Por ejemplo, un 68\% de los participantes afirman que los niños son más activos, y sólo un $26 \%$, dice que son las mujeres; un $6 \%$ dice que los niños son más obedientes frente a un $81 \%$ que afirma que son las niñas; un $65 \%$ asegura que los niños son más originales, mientras que un $32 \%$ dice que son las niñas. Se nota una inclinación hacia ciertas cualidades para los niños y otras para las niñas.

\section{CUADRO $\mathrm{N}^{\circ} 2$}

CARACTERÍSTICAS QUE POSEEN SUS ALUMNOS Y ALUMNAS

\begin{tabular}{|l|c|c|c|c|c|c|}
\hline \multirow{2}{*}{ CRITERIOS } & \multicolumn{2}{|c|}{ NIÑOS } & \multicolumn{2}{c|}{ NIÑAS } & \multicolumn{2}{c|}{ AMBOS } \\
\cline { 2 - 7 } & Abs. & $\%$ & Abs. & $\%$ & Abs. & \% \\
\hline Agresivos (as) & 29 & 94 & 0 & 0 & 2 & 6 \\
Desordenados (as) & 21 & 68 & 6 & 19 & 4 & 13 \\
Desobedientes & 22 & 71 & 8 & 26 & 1 & 3 \\
Irrespetuosos (as) & 29 & 94 & 1 & 3 & 1 & 3 \\
Indisciplinados (as) & 24 & 77 & 6 & 20 & 1 & 3 \\
\hline
\end{tabular}


Se observa en el cuadro $\mathrm{N}^{\circ} 2$ que un $94 \%$ de los participantes, asegura que los niños son más agresivos e irrespetuosos que las niñas; un $68 \%$ afirma que los niños son más desordenados y sólo un $19 \%$ dice que las niñas también; un $71 \%$ y un $77 \%$ dice además que los niños son más desobedientes e indisciplinados, que las niñas. Los y las participantes que le asignan a ambos géneros las anteriores características son muy pocos, el porcentaje osciló entre el $13 \%$ y $3 \%$.

$\mathrm{Al}$ igual que en cuadro anterior, se refleja una tendencia hacia un modelo impuesto por el medio social y cultural, en este caso, se le atribuye al niño la mayoría de las características negativas. Es así como, los y las docentes y administrativos, aseguran que los niños son más agresivos, desordenados, desobedientes, irrespetuosos e indisciplinados.

En síntesis, se observa que en estas instituciones educativas los resultados muestran que hay mucho por hacer en materia de género. Específicamente con respecto a la formación y capacitación del personal administrativo y docente.

\section{GRÁFICO No 1 \\ ¿POR QUÉ CONSIDERA USTED QUE REALIZAN SUS ALUMNOS Y ALUMNAS LAS MISMAS FUNCIONES EN EL AULA?}

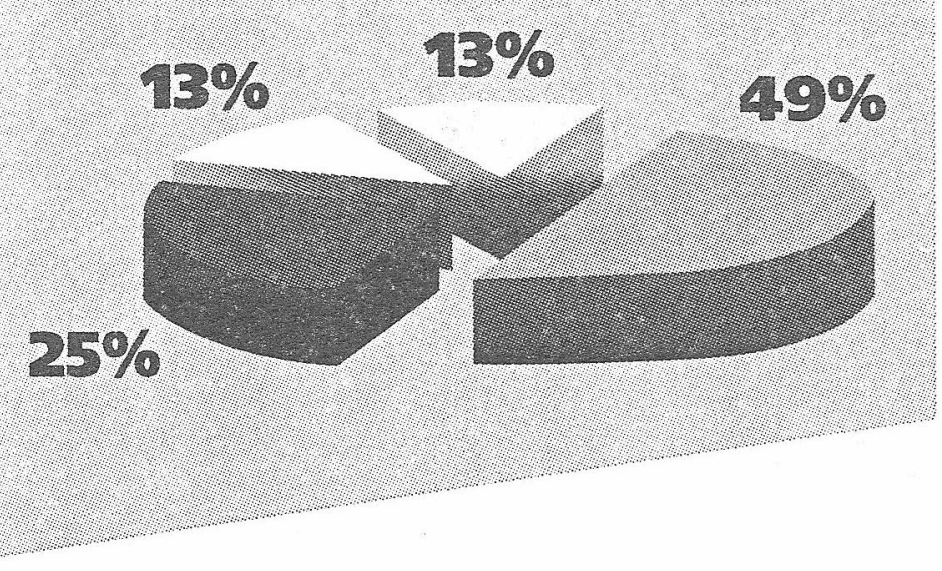


De acuerdo con la experiencia de las y los docentes encuestados, las y los estudiantes realizan en un $49 \%$, las mismas funciones, es decir, desarrollan los mismos trabajos, tienen iguales obligaciones y no se hace distinción de sexo.

\section{OPINIÓN DE LOS ALUMNOS Y LAS ALUMNAS.}

El segundo objetivo consistió en analizar la actitud de los alumnos y alumnas, en actividades que involucran la igualdad de género. Los siguientes cuadros y gráficos muestran los resultados obtenidos en las escuelas Gran Samaria y Llorente de Flores.

\section{GRÁFICO N 2 \\ ACERCA DE SÍ LOS HOMBRES Y LAS MUJERES REALIZAN LAS MISMAS FUNCIONES EN EL AULA}



FUENTE: Cuestionario para niños y niñas de segundo y cuarto grados.

Podemos observar que un $87 \%$ de las y los estudiantes consultados, opinan que los hombres y las mujeres no realizan las mismas funciones en el aula. Al solicitarles que las mencionaran, ellos indicaron que en su mayoría las mujeres barren, limpian y ordenan y los hombres hacen mandados, reparten libros y borran la pizarra. 
Además, se encontró una contraposición, con respecto a la opinión de las y los docentes que aseguraron que las alumnas y los alumnos realizan las mismas funciones, según lo analizado en el cuadro anterior.

\section{CUADRO $\mathrm{N}^{\circ} 3$ \\ CUALIDADES QUE POSEEN LOS HOMBRES Y LAS MUJERES}

\begin{tabular}{|l|c|c|c|c|c|c|}
\hline \multirow{2}{*}{ CRITERIOS } & \multicolumn{2}{|c|}{ NIÑOS } & \multicolumn{2}{c|}{ NIÑAS } & \multicolumn{2}{c|}{ AMBOS } \\
\cline { 2 - 7 } & Abs. & $\%$ & Abs. & $\%$ & Abs. & $\%$ \\
\hline Inteligentes & 64 & 70 & 28 & 30 & - & - \\
Ordenados (as) & 33 & 36 & 51 & 55 & 8 & 9 \\
Disciplinados (as) & 31 & 34 & 56 & 61 & 5 & 5 \\
Responsables & 33 & 36 & 55 & 60 & 4 & 4 \\
Obedientes & 41 & 45 & 51 & 55 & - & - \\
Cariñosos (as) & 32 & 35 & 58 & 63 & 2 & 2 \\
\hline
\end{tabular}

FUENTE: Cuestionario para estudiantes.

En el cuadro $\mathrm{N}^{\circ} 3$, un $70 \%$ de las y los estudiantes dicen que los niños son más inteligentes, y solamente, un $30 \%$ manifiesta que son las niñas; un $36 \%$ afirma que los niños son ordenados frente a un $55 \%$ que dice que son las niñas; un $61 \%$ opina que las niñas son más disciplinadas y un $34 \%$ que son los niños; un $60 \%$ asegura que las niñas son más responsables, mientras que un $36 \%$ dice que son los niños. Un $63 \%$ plantea que las niñas son más cariñosas frente a un $35 \%$ que manifiesta que son los niños más cariñosos que las niñas.

El gráfico 3 permite observar que el $76,9 \%$ de las personas consultadas afirman que son más ordenadas las mujeres. Mientras que un 15,4\% manifiestan que son los hombres los más ordenados. Un porcentaje de 7,7\% señala que ambos son igualmente ordenados y ordenadas.

\section{CONSIDERACIONES FINALES}

Como parte del trabajo de investigación para optar por el grado de Licenciatura en la División de Educación Rural del CIDE, surgió la siguiente propuesta. Para llevarla a la práctica, es indispensable sensibilizar a los 


\section{GRÁFICO N ${ }^{\circ} 4$}

\section{¿QUIÉNES SON MÁS ORDENADOS U ORDENADAS?}

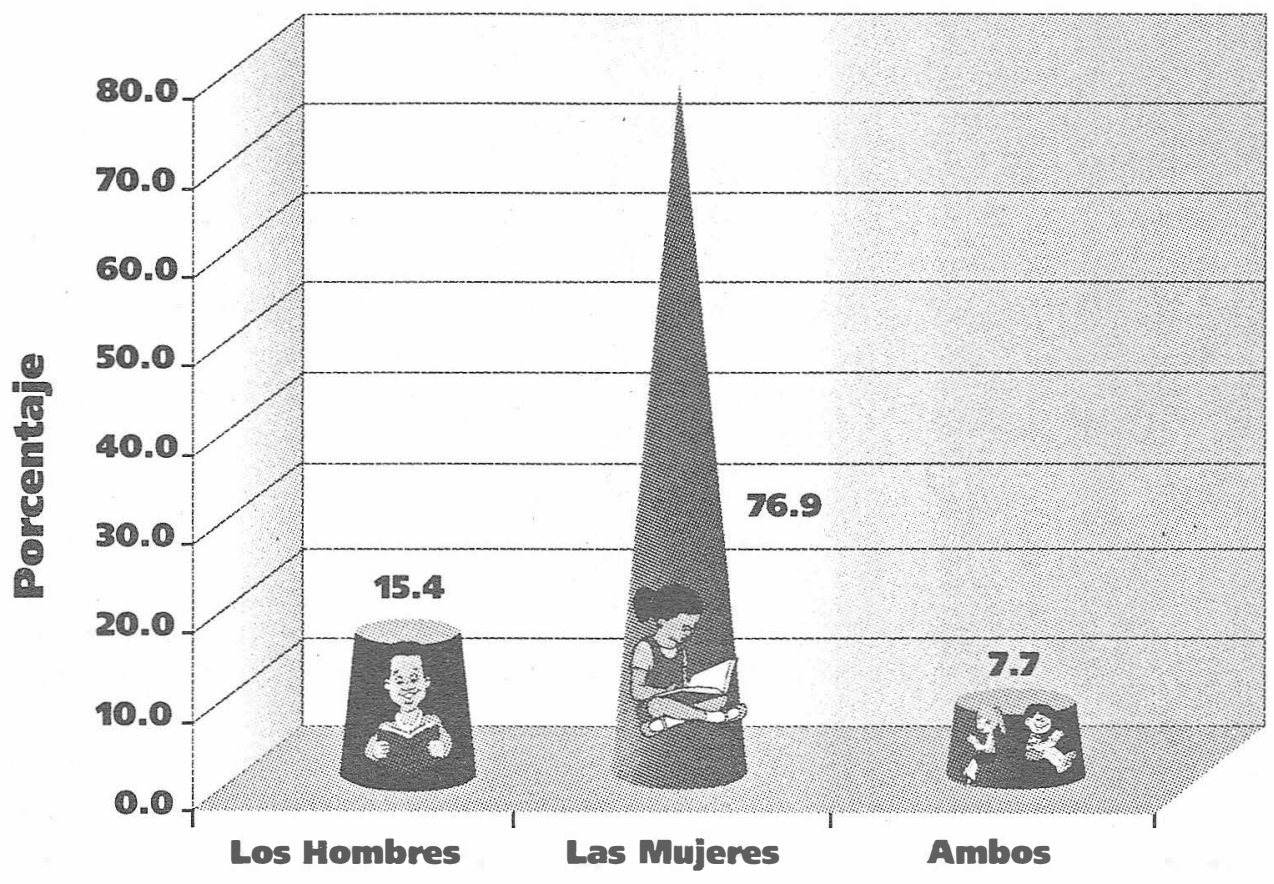

docentes y las docentes en la importancia de erradicar las prácticas discriminatorias. Solo un educador y una educadora sensibilizados podrán planificar sus lecciones desde una perspectiva de género.

Además, es necesario, que el o la docente logre mantener un ambiente de confianza, respeto y que enseñe con su ejemplo. 


\section{REFERENCIAS}

Abarca, S. (1991) Métodos cualitativos en investigación sobre la enseñanza. s.o.d. Aguilar, L., Facio, A. y otros. (1995) ¿Feminismo en Costa Rica? (Testimonios, reflexiones, ensayos). San José, Costa Rica.

Calvo, Y. (1990) A la mujer por la palabra. Heredia, Costa Rica.

Calvo, Y. (1984) Literatura, mujer y sexismo. San José, Costa Rica.

Contreras, I. (1992) Investigación etnográfica en el marco de la investigación cualitativa en educación. S.O.D.

González, M. (1992) El sexismo en educación: discriminación cotidiana. San José, Costa Rica.

Martínez, M. (1991) La investigación cualitativa: estrategias en educación. Caracas, Venezuela.

Ministerio de Educación Pública. Centro Nacional de Didáctica. (1995) Yo, mi familia, mi comunidad: Manual de apoyo didáctico. Tercer año. Primer ciclo de la EGB.

Ministerio de Educación Pública. Centro Nacional de Didáctica. (1998) Formación ambiental demográfica, familiar y personal; manual de apoyo didáctico. Primer y segundo ciclo de la EGB.

Ministerio de Justicia y Gracia. (1997) Ley de la promoción de la igualdad real de la mujer. San José, Costa Rica.

Ministerio de Justicia y Gracia (1987) ¿Qué es la defensoría de la infancia? San José, Costa Rica.

Montero, M. (1983) La investigación cualitativa en el campo de la educación. San José, Costa Rica.

Patrick, S. (1988) Introducción a la investigación y a la evaluación educativa. Instituto de investigaciones y mejoramiento educativo. Universidad de San Carlos de Guatemala.

Programa de estudios interdisciplinario de estudios de género de Nicaragua. (1987) Guía didáctica. Nicaragua.

Salas, F. (1997) La investigación educativa: compartiendo ideas fundamentales. Centro de Investigación y Docencia en Educación. Universidad Nacional. 
UNIVERSIDAD NACIONAL

CENTRO DE INVESTIGACIÓN Y DOCENCIA EN EDUCACIÓN DIVISIÓN RURAL

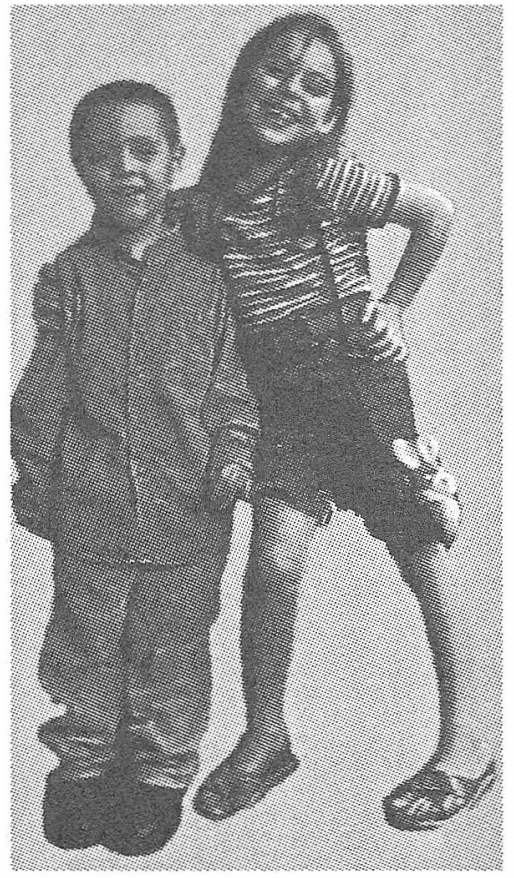

\title{
LIBRO DE TRABAJO
}

\section{“IGUALDAD DE GÉNERO”}

PROFESORA:

\author{
YISENIA SOLÍS PÉREZ
}

HEREDIA

2005 


\section{CUADERNO DE TRABAJO PARA PRIMERO Y SEGUNDO CICLOS}

\section{"IGUALDAD DE GÉNERO EN EL AULA ESCOLAR"}

\section{PRESENTACIÓN}

Este cuaderno de trabajo consta de dieciocho estrategias metodológicas, las cuales, el o la docente puede aplicar en el aula escolar, para fomentar o desarrollar la igualdad de género entre sus estudiantes.

Las experiencias que se plantean, proporcionan a los y las niñas la motivación suficiente para que sientan la necesidad de vivir la igualdad de género en la escuela y por qué no, en el hogar.

Se tomó en cuenta al elaborar este documento, los intereses y necesidades de los y las docentes, esperando sea un material provechoso para las y los profesionales en educación.

\section{INTRODUCCIÓN}

Querido(a) estudiante:

En este cuaderno de trabajo podrás escribir, pintar, recortar, leer y expresar las opiniones y sentimientos libremente, sobre temas relacionados con los derechos y deberes que como ser humano posees.

Espero que puedas realizar con mucho cariño y dedicación cada actividad, que está hecha especialmente para usted y que le ayudará a mejorar las relaciones con las y los compañeros y te permitirá a la vez crecer como persona. 
1- ESTRA'TEGIA METODOLÓGICA: La mujer taxista.

\section{2- DESCRIPCIÓN DE LA TÉCNICA}

Lectura de un fragmento acerca de un trabajo que en la mujer es poco común.

3- OBJETIVO: Conocer la opinión de los niños y las niñas acerca de los diferentes trabajos que puede desempeñar una mujer.

4- TIEMPO: Una lección, 40 minutos.

\section{PROCEDIMIENTO:}

1- Leo lo siguiente:

Lucía acaba de encontrar trabajo como taxista. Llega y estaciona su taxi frente a su grupo de amigos y amigas, estos la miran sorprendidos...

¿Qué le dijeron los amigos y amigas a Lucía?

2- Ilustro el texto.

3- EVALUACIÓN: Leo en forma oral la historia y realizamos una plenaria. 
1- ESTRATEGIA METODOLÓGICA: Caperucita Roja.

\section{2- DESCRIPCIÓN}

Cambiarle de género al personaje principal del cuento Caperucita Roja.

3- OBJETIVO: Demostrar la igualdad de género que existe.

4- TIEMPO: Una lección, 40 minutos.

\section{5- PROCEDIMIENTO:}

1- Escucho èl cuento "Caperucita Roja “

2- Construyo el cuento cambiando de personaje, en vez de Caperucita va a ser Caperucito.

3- Ilustro.

4- EVALUACIÓN: En una plenaria comentamos los cambios que hicimos y explicamos el porqué. 
1- ESTRATEGIA METODOLÓGICA: Láminas.

\section{2- DESCRIPCIÓN:}

Se presenta una lámina en donde se observa una mujer realizando un trabajo poco común, posteriormente se dará una opinión sobre la misma.

3- OBJETIVO: Expreso mi opinión sobre la lámina observada.

4- TIEMPO: Una lección, 40 minutos.

5- PROCEDIMIENTO:

1- Observo la lámina y doy mi opinión.
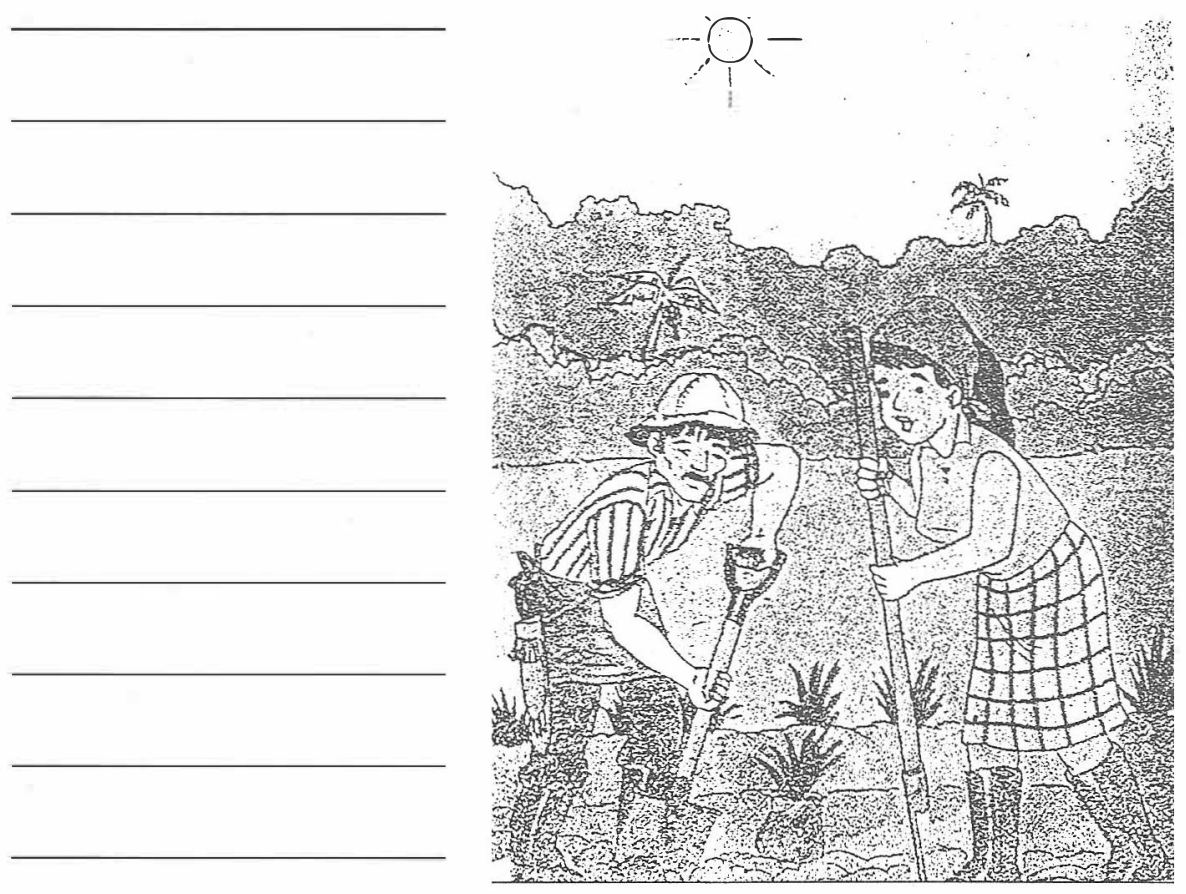

6- EVALUACIÓN: Se obtendrá de acuerdo a la opinión de alumnas y alumnos un porcentaje acerca de quiénes están de acuerdo en los trabajos que ahí se realizan. 
1- ESTRATEGIA METODOLÓGICA: Mujeres sobresalientes.

\section{2- DESCRIPCIÓN:}

Buscar en el periódico algunas láminas que destaquen funciones importantes que realizan algunas mujeres.

3- OBJETIVO: Destacar la labor sobresaliente de mujeres en la vida pública y política.

4- TIEMPO: Dos lecciones, 80 minutos.

\section{5- PROCEDIMIENTO:}

1- Se le da a un alumno la foto de una mujer que haya sobresalido en la vida pública costarricense de la lámina y luego de conocer su experiencia, anota 5 funciones importantes realizadas por ella:

1

2

3

4

5 